\section{Correspondence to: 'Combination of human umbilical cord mesenchymal (stromal) stem cell transplantation with IFN- $\gamma$ treatment synergistically improves the clinical outcomes of patients with rheumatoid arthritis'}

We read with great interest the article by $\mathrm{He} e t$ al, which the authors reported that mesenchymal stem cell (MSC) transplantation (MSCT) plus interferon- $\gamma$ (IFN- $\gamma$ ) combination therapy may realise clinical efficacy featuring good or moderate EULAR responses in patients with rheumatoid arthritis (RA) who responded poorly to conventional therapeutics including disease-modifying antirheumatic drugs. ${ }^{1}$ MSC-based therapies have become novel therapeutic approaches for RA through immunomodulation, including the induction of $\mathrm{T}$ regulatory cells (Treg). ${ }^{2}$ We agree with the authors that IFN- $\gamma$-primed MSCs may bring about improved immunomodulation in vitro (as suggested in Figure 2 by He $e t a l^{1}$ ), and propose that the results based on studies in patients could be juxtaposed with further evidence on the protocol of IFN- $\gamma$ treatment, serum levels of IFN- $\gamma$ in patients and gating strategies for flow cytometry (FC) analysis.

As the therapeutic effect of MSCT for RA is regulated by endogenous IFN- $\gamma$ level, ${ }^{3}$ the clinical protocol of IFN- $\gamma$ treatment in this study involved intramuscular infusion of IFN- $\gamma .{ }^{1}$ On the contrary, the protocol adopted in vitro was IFN- $\gamma$ priming using MSCs pretreated with IFN- $\gamma$ for 24 hours (as mentioned in the MSC and T cell co-culture section in Supplementary Materials by $\mathrm{He} e \mathrm{al}^{1}$ ), which would allow for potentiated immunomodulatory functions of MSCs. However, compared with transplanting MSCs primed with IFN- $\gamma$, the intramuscular infusion of IFN- $\gamma$ may initiate further immune reactions ${ }^{45}$ that have yet been pinpointed in this study. ${ }^{1}$ From a translational standpoint, interpreting the safety of IFN- $\gamma$-primed MSC protocols as that of recombinant IFN- $\gamma$ monotherapy, should be not appropriate. As a result, the discrepancy between these protocols could attribute to underestimated complications of the combination therapy.

Although IFN- $\gamma$ has been proven as a foremost mediator for the inflammatory responses in RA, ${ }^{6}$ which has also been evidenced by its interactions with MSCT in the murine model (as suggested in Figure S2 by He $e t a l^{1}$ ), whether MSCT plus intramuscular infusion of IFN- $\gamma$ would further modulate serum levels of IFN- $\gamma$ in patients remains unclear. While the authors observed alleviated inflammatory responses in terms of serum levels of erythrocyte sedimentation rate, $\mathrm{C}$ reactive protein, anti-cyclic citrullinated peptide and rheumatoid factor among patients (as suggested in Figure 3 by $\mathrm{He} e t \mathrm{al}^{1}$ ), serum level monitoring of IFN- $\gamma$, or other proinflammatory cytokines such as tumor necrosis factor (TNF)- $\alpha$, interleukin (IL)- $1 \alpha$ or IL- $1 \beta$, may facilitate our understanding of the effect of IFN- $\gamma$ infusion, as well as whether their concomitant presence induced the immunosuppressive functions of MSCs.

Furthermore, gating as a data reduction technique for FC analytics, often involves certain controls to ensure proper interpretation. For instance, the Fluorescence Minus One control technique, has been used to recognise cells presenting as data spread arise from multiple fluorochromes. ${ }^{7}$ Likewise, isotype controls allow for identification of the background binding caused by antibody isotypes. ${ }^{78}$ It is possible that the gauged percentages of $\mathrm{CD} 3+$ and IFN- $\gamma+$ MSCs, and the estimated baseline for groups without IFN- $\gamma$ treatment (as suggested in Figure 2 by He $e t a l^{1}$ ), could differ among different control techniques for gating.

For the above reasons, we propose that the conversations between bench side and bedside considerations are necessary for developing translational models and cell therapies for RA. For instance, following up the serum levels of IFN- $\gamma$ and adopting control techniques for FC gating may improve our knowledge on the effectiveness of the treatment protocol and infusion of IFN- $\gamma$ in MSCT.

\section{Kevin Sheng-Kai Ma $\odot{ }^{1}{ }^{1}$ Li-Tzu Wang, ${ }^{2}$ Shin-Yi Tsai ${ }^{1}$}

${ }^{1}$ Department of Health Policy and Management, Johns Hopkins University Bloomberg School of Public Health, Baltimore, Maryland, USA

${ }^{2}$ Institute of Cellular and System Medicine, National Health Research Institutes, Zhunan, Taiwan

Correspondence to Dr Kevin Sheng-Kai Ma, Department of Health Policy and Management, Johns Hopkins University Bloomberg School of Public Health, Baltimore, MD 21218, USA; sheng.kai.ma@cern.ch

Contributors All authors have equal contribution on drafting the article.

Funding The authors have not declared a specific grant for this research from any funding agency in the public, commercial or not-for-profit sectors.

Competing interests None declared.

Patient and public involvement Patients and/or the public were not involved in the design, or conduct, or reporting, or dissemination plans of this research.

Patient consent for publication Not required.

Provenance and peer review Not commissioned; internally peer reviewed.

(c) Author(s) (or their employer(s)) 2020. No commercial re-use. See rights and permissions. Published by BMJ.

\section{(A) Check for updates}

To cite Ma KS-K, Wang L-T, Tsai S-Y. Ann Rheum Dis Epub ahead of print: [please include Day Month Year]. doi:10.1136/annrheumdis-2020-218704

Received 26 July 2020

Accepted 31 July 2020

\section{Linked}

- https://doi.org/10.1136/annrheumdis-2020-218762

Ann Rheum Dis 2020;0:1. doi:10.1136/annrheumdis-2020-218704

ORCID iD

Kevin Sheng-Kai Ma http://orcid.org/0000-0003-1056-1533

\section{REFERENCES}

1 He X, Yang Y, Yao M, et al. Combination of human umbilical cord mesenchymal stem (stromal) cell transplantation with IFN- $\gamma$ treatment synergistically improves the clinical outcomes of patients with rheumatoid arthritis. Ann Rheum Dis 2020:annrheumdis-2020-217798.

2 Liu L, Wong CW, Han M, et al. Meta-Analysis of preclinical studies of mesenchymal stromal cells to treat rheumatoid arthritis. EBioMedicine 2019;47:563-77.

3 Yang $Y, H e X$, Zhao R, et al. Serum IFN- $\gamma$ levels predict the therapeutic effect of mesenchymal stem cell transplantation in active rheumatoid arthritis. J Trans/ Med 2018;16:165.

4 Zaidi MR, Merlino G. The two faces of interferon- $\gamma$ in cancer. Clin Cancer Res 2011;17:6118-24.

5 Hu X, Ivashkiv LB. Cross-Regulation of signaling pathways by interferon-gamma: implications for immune responses and autoimmune diseases. Immunity 2009:31:539-50.

6 Ivashkiv LB. IFN $\gamma$. signalling, epigenetics and roles in immunity, metabolism, disease and cancer immunotherapy. Nat Rev Immunol 2018;18:545-58.

7 Maecker HT, Trotter J. Flow cytometry controls, instrument setup, and the determination of positivity. Cytometry A 2006;69:1037-42.

8 Feher K, Kirsch J, Radbruch A, et al. Cell population identification using fluorescenceminus-one controls with a one-class classifying algorithm. Bioinformatics 2014:30:3372-8. 